khả năng phẫu thuât. 131 bênh nhân hóa xa trị đồng thời với phác đồ FOLFOX, 128 bệnh nhân hóa xạ trị đồng thời với phác đồ $C F$, nhận thây tất cả các biến cố độc tính nghiêm trọng xảy ra trên $5 \%$ bệnh nhân ở cả 2 nhóm, nhưung độc tính độ 3-4 giữa 2 nhóm sự khác biệt không có ý nghĩa thống kê. Các triệu chứng như chán ăn, độc tính thần kinh, tăng men gan xảy ra tỉ lệ cao hơn ở nhóm điều trị FOLFOX, các triệu chứng tăng creatinin, rụng tóc, viêm niêm mạc, tỉ lệ giảm bach câu, bạch câu trung tính, tiểu cầu xảy ra phổ biến hơn ở nhóm điều trị CF [7]

Đặc điểm tác dụng phụ do hóa chất trên nhóm bệnh nhân nghiên cứu của chúng tôi thấp hơn so với nghiên cứu của tác giả Nguyễn Đức Lợi có thể do chúng tôi dùng phác đồ hóa chất FOLFOX trong đó oxaliplatin được cho là độc tính thấp hơn cisplatin[8]. Chức năng thận của các bênh nhân trong nghiên cứu của chúng tôi sau điều trị đều nằm trong giới hạ bình thương, không có bệnh nhân nào bị giảm mức lọc cầu thận. Sau điều trị, có 5 bệnh nhân (15.6\%) trong nghiên cứu của chúng tôi có tình trạng tăng men gan AST, ALT ở độ 1 , có 2 bệnh nhân tăng creatinin độ 1 .

\section{KẾT LUẬN}

Hóa xạ trị đồng thời UTTQ sử dụng kĩ thuật xạ trị điều biến liều đồng thời phác đồ FOLFOX có những kết quả ban đầu khả quan về tỉ lệ đáp ứng tốt, giảm tác dụng phụ. Cân tiếp tục tiến hành nghiên cứu với số lượng bệnh nhần lớn hơn và trong thời gian theo dỗi dài hơn để thu được kết quả khách quan.

\section{TÀI LIÊU THAM KHẢO}

1. Freddie Bray, Jacques Ferlay, Isabelle SorJomataram et al (2018), Global Cancer Statistics 2018: GLOBOCAN Estimatesof Incidence and Mortality Worldwide for 36 Cancersin 185 Countries; CA Cancer J Clin 2018; 25-31.

2. Honing J, Smit JK, Muijs CT et al (2014). A comparison of carboplatin and paclitaxel with cisplatinum and 5-fluorouracil in definitive chemoradiation in esophageal cancer patients. Ann Oncol. 25(3): 638-43

3. Conroy $T$, Galais MP, Raoul $J L$, et al (2014). Definitive chemoradiotherapy with FOLFOX versus fluorouracil and cisplatin in patients with oesophageal cancer (PRODIGE5/ ACCORD17): final results of a randomised, phase 2/3 trial. Lancet Oncol . 15:305-314.

4. Clinical Practice Guidelines in Oncology (2015). Esophageal and Esophagogastric Junction cancers. NCCN Guidelines version 3.2015. 51.

5. Haefner et al (2017). Intensity - modulated versus 3 - dimensional conformal radiotherapy in the definitive treatment of esophageal cancer: comparison of outcomes and acute toxicity. Radiation Oncology. 2017; 12:13.

6. Makoto Ito, Takeshi Kodaira, Hiroyuki Tachibama et al (2017).Clinical results of definitive chemoradiotherapy for cervical esophageal cancer: Comparison of failure pattern and toxicities between intensity - modulated radiotherapy and 3 - dimensional conformal radiotherapy. Head neck.2017 Dec;39(12):2406-2415

7. Galais MP Conroy T, Raoul JL et al. (2014), Definitive chemoradiotherapy with FOLFOX versus fluorouracil and cisplatin in patient with oesophageal cancer (PRODIGE5/ACCORD17): final results of a randomised, phase $2 / 3$ trial, Lancet Oncology, 15, tr. 305-314

8. Nguyến Đức Lợi (2015) Đánh giá hiệu quả phác đồ hóa xa tri đônng thời và một số yếu tố tiên lương ung thư biểu mô thức quản giai đoan III, IV tại bệnh viện $\mathrm{K}$, Luận án tiến sĩ y khoa, Đại học Y HN.

\title{
RỐI LOAN CHỨC NĂNG TÌNH DƯC Ở BÊNHH NHÂN SUY TIM CHỨC NĂNG TẦM THU THẤT TRÁI GIẢM VÀ MộT SỐ YẾU TỐ LIÊN QUAN
}

Bùi Văn Nhơn ${ }^{1,2}$, Trần Tuấn Việt ${ }^{1,3}$,
Bùi Văn Tùng1, Bùi Thị Oanh ${ }^{1}$

\section{TÓM TẮT}

Muc tiêu: Mô tả tỷ lê rối loan chức năng tình dục ở bệnh nhân suy tim chức năng tâm thu thất trái giảm

\footnotetext{
${ }^{1}$ Trường Đai hoc Y Hà Nôi

²Bênh viện Đại học Y Hà Nội

${ }^{3}$ Viện Tim mạch Việt Nam

Chịu trách nhiệm chính: Bùi Văn Nhơn

Email: drbuinhon@hmu.edu.vn

Ngày nhận bài: 2/3/2021

Ngày phản biên khoa hoc: 25/3/2021

Ngày duyệt bài: 15/4/2021
}

và một số yếu tố liên quan tại Viện Tim mạch Việt Nam. Đối tượng và phương pháp: Nghiên cứu mô tả cắt ngang xác định rối loạn chức năng tình dục ở bênh nhân nữ dưa vào bộ câu hỏi FSFI, rối loan cương dương ở bệnh nhân nam dựa vào bộ câu hỏi IIEF. Kết quả: Tỷ lê suy giảm chức năng sinh duc nữ với $77,3 \%$; rối loạn cương dương ở nam $88,9 \%$; rối loan chức năng tình dục nữ và rối loạn cương dương có liên quan đến tuổibệnh nhân suy tim. Kết luận: Rối loạn chức năng tình dục nữ và rối loạn cưởng dương ở bênh nhân suy tim chức năng tâm thu thất trái giảm với tỷ lệ cao, có tương quan với tuổi của bệnh nhân suy tim. 
Tư khóa: Suy tim; Rối loạn chức năng tình dục nữ; Rối loạn cương dương.

\section{SUMMARY \\ SEXUAL DYSFUNCTION IN CHRONIC HEART FAILURE PATIENTS WITH REDUCED EF AND SOME RELATED FACTORS}

Objective: To describe the prevalance of sexual dysfunction and some related factors in chronic heart failure patients with reduced EF at Vietnam National Heart Institute. Methods: A cross-sectional study was conducted to asess sexual dysfunction in HFrEF patients in Vietnam National Heart Institute at Bach Mai hospital. We used FSFI questionares for female patients and IIEF for assessing erectile function of male patients. Results: The female sexual dysfunction was $77.3 \%$; erectile dysfunction in male patients was $88.9 \%$. The univariate analysis indicated risk factors for sexual dysfunction was age $(p<0.05)$. Conclustion: Our data showed a high prevalence of sexual dysfunction in HFrEF patients. The risk factors for sexual dysfunction among studied subjects was age groups.

Keywords: Chronic heart failure, female sexual dysfunction and erectile dysfunction.

\section{I. ĐĂT VẤN ĐỀ}

Suy tim là bênh tim mạch có tốc độ gia tăng nhanh nhất, tỷ lệ mắc tăng dần theo tuổi. Tỷ lê hiện mắc suy tim có xu hướng gia tăng nhanh chóng, chiếm khoảng $2-3 \%$ dân số và lên đến 10-20\% ở nhóm trên 70 tuổi. Suy tim là vấn đề sức khoẻ toàn câu ảnh hưởng đến hàng triệu người trên thế giới[1]. Kéo theo đó chất lượng cuộc sống của bệnh nhân suy tim cũng bị ảnh hưởng nghiêm trọng, đặc biệt là các hoạt động tình dục[2]. Rối loạn hoat động tình dục ở bệnh nhân suy tim là khá phổ biến, chủ yếu là các rối loạn cương dương ở nam giới và giảm ham muốn tình dục ở nữ giới[3]. Theo nghiên cứu ở Hà Lan tiến hành ở 438 bệnh nhân suy tim cho thấy, có $59 \%$ bệnh nhân có vấn đề về tình dục, chủ yếu là rối loạn cương dương, đặc biệt là ở những bệnh nhân trẻ tuổi và ở những người có ban tình. Một số nghiên cứu khác cho thây có khoảng $60 \%$ đến $87 \%$ bệnh nhân suy tim có vấn đề về tình dục, bao gồm giảm hứng thú và hoạt động tình dục, trong đó một phần tư có báo cáo dừng hoàn toàn các hoạt động tình dục[4]. Các vấn đề tình dục thường liên quan chặt chẽ đến triệu chứng của suy tim. Bệnh nhân suy tim khi hoạt động tình dục thường bị rối loạn về tâm lý, nhiều người báo cáo gặp khó khăn khi quan hệ tình dục và sợ bị đột từ trong khi quan hệ tình dục do tăng nhịp tim và tăng huyết áp[5]. Bệnh nhân thường lo lắng vì vậy sẽ ảnh hưởng tiêu cực đến chất lượng cuộc sống của ho[6],[7]. Tại Việt Nam các nghiên cứu về rối loạn tình dục ở bênh nhân suy tim còn rất hạn chế. Nghiên cứu về rối loạn tình dục ở bệnh nhân suy tim là cần thiết, góp phần nâng cao chất lượng cuộc sống cho bênh nhân suy tim, đặc biệt là đời sống về tình duc. Do đó chúng tôi thực hiên nghiên cứu này với mục tiêu mô tả tỷ lệ rối loạn chức năng tình dục ở bệnh nhân suy tim chức năng tâm thu thất trái giảm và một số yếu tố liên quan tại Viện Tim mach Việt Nam.

\section{II. ĐỐI TƯỢNG VÀ PHƯƠNG PHÁP NGHIÊN CỨU}

1. Đối tượng nghiên cứu: gồm 50 bệnh nhân từ 18 đến 60 tuổi.

Tiêu chuẩn lựa chọn: Bệnh nhân có chẩn đoán suy tim (> 6 tháng) với chỉ số EF giảm, NYHA I - III, không sử dụng các thuốc điều trị suy giảm chức năng tình dục, rối loạn cương dương. Bệnh nhân đồng ý tham gia nghiên cứu. Bệnh nhân có vợ/chồng, bạn tình khỏe mạnh.

Tiêu chuânn loai trư:' Có rối loạn tâm lý: stress, trầm cảm, không có khả năng giao tiếp... Mắc bệnh lýđường sinh dục như: chấn thương, viêm tinh hoàn, khối u tinh hoàn... Chấn thương tủy sống, cột sống, phẫu thuật. Rối loạn chức năng các tuyến nội tiết: rối loạn chức năng vùng dưới đồi-tuyến yền, rối loạn chức năng tuyến giáp... Không hợp tác nghiên cứu.

\section{Phương pháp nghiên cứu}

Thiết kế nghiên cứu:Nghiên cứu mô tả cắt ngang được thực hiện ở 50 bênh nhân từ tháng 5/2019 đến tháng 6/2020 với cách chọn mẫu thuân tiên.

Công cụ nghiên cứu và kỹ thuật thu thập số liệu. Phỏng vấn thu thập các thông tin cá nhân, tiển sử bệnh, bệnh kết hợp, triệu chứng lâm sàng bênh suy tim.

Phỏng vấn tình trạng suy chức năng tình dục nữ bằng bộ câu hỏi FSFI[8] và tình trạng rối loạn cương dương bằng bộ câu hỏi IIEF[9].

Xử lý số liêuu: số liệu được làm sạch và quản lý trên phần mềm SPSS 20.0. Số liệu được trình bày dưới dạng tần suất, tỷ lệ \%. Sử dụng test Khi bình phương để phân tích một số yếu tố liên quan. Mức ý nghĩa thống kê với $\mathrm{p}<0,05$.

Đạo đức nghiên cứu: Bệnh nhân được giải thích về mục tiếu nghiên cứu, đồng ý chấp thuận tham gia nghiên cứu. Tất cả thông tin cá nhẩn của bệnh nhân được bảo mật, câu trả lời của bệnh nhân được mã hóa. Bệnh nhân có quyền dừng tham gia nghiên cứu bất kỳ thời điểm nào mà không bị phân biệt trong quá trình chẩn đoán và điều trị.

\section{KẾT QUẢ NGHIÊN CỨU}

Nghiên cứu được thực hiện trên 50 bệnh 
nhân kết quả cho thấy: tỉ lệ bênh nhân nam chiếm $56 \%$ và bệnh nhân nữ chiểm $44 \%$.Độ tuổi của bệnh nhân tham gia nghiên cứu từ 18 tuổi đến 60 tuổi với độ tuổi trung bình là 49,5 tuổi. Phần lớn sống ở khu vực nông thôn 39 bệnh nhân $(78 \%)$ và hầu hết là nông dân/ công nhân: 25 bệnh nhân (50\%). Những người góa, độc thân và ly dị chiếm $12 \%$.

Đặc điểm về rối loạn chức năng tình dục

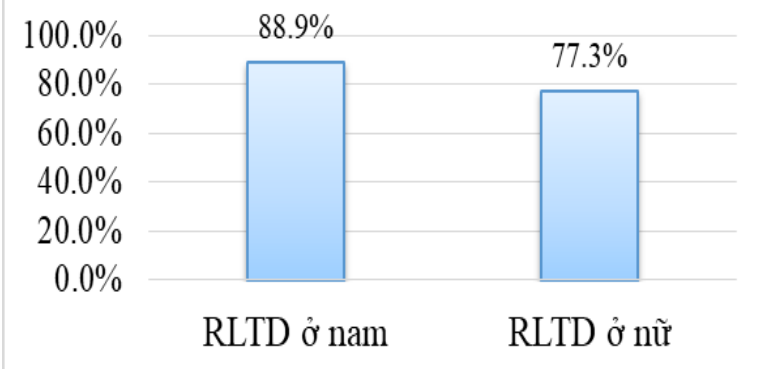

Biểu đồ 1. Tỷ lệ rôi loạn chức năng tình dục theo giới tính

Tỷ lệ rối loan chức năng tình dục rất cao với 84\% ( $n=42)$ trong số 50 bệnh nhân, chỉ có 8 bệnh nhân (16\%) báo cáo không có rối loạn chức năng tình dục. Trong đó tỷ lệ nam giới mắc rối loạn chức năng tình dục là $88,9 \%$, tỷ lệ này ở nữ giới là $77,3 \%$.

Bảng 1. Điểm IIEF ở bệnh nhân nam và FSFI ở bệnh nhân nữ

\begin{tabular}{|c|c|c|}
\hline Đặc điểm & Mean & SD \\
\hline Tống điếm IIEF & $\mathbf{3 5 , 4}$ & $\mathbf{1 7 , 1}$ \\
\hline Chức năng cương dương & 15,8 & 7,9 \\
\hline Cực khoái & 4,5 & 2,4 \\
\hline Ham muốn & 5,3 & 1,7 \\
\hline Thỏa mãn & 10,5 & 6,1 \\
\hline Tống điếm FSFI & $\mathbf{1 8 , 6 1}$ & $\mathbf{7 , 7}$ \\
\hline Ham muốn & 3,4 & 1,5 \\
\hline Hưng phấn & 3,1 & 1,6 \\
\hline Tiết dịch & 3,0 & 1,3 \\
\hline Cực khoái & 2,6 & 1,3 \\
\hline Thỏa mãn & 3,5 & 1,6 \\
\hline Đau & 2,9 & 1,4 \\
\hline
\end{tabular}

Điểm IEFI về chức năng sinh dục nam là 35,4 $\pm 17,1$. Trong 4 lĩnh vực chức năng tình dục của nam giới, điểm chức năng cương là cao nhất với 15,8 \pm 7,9.Ở bệnh nhân HFrEF nữ, tổng điểm FSFI là $18,61 \pm 7,7$. Trong khi đó, ham muốn tình duc, kích thích, bôi trơn, cực khoái, thỏa mãn và đau đớn lần lượt là $3,4 \pm 1,5,3,1 \pm 1,6$, $3 \pm 1,3,2,6 \pm 1,3,3,5 \pm 1,6$ và $2,9 \pm 1,4$.

Rối loạn chức năng cương dương ở bệnh

\section{nhân nam}

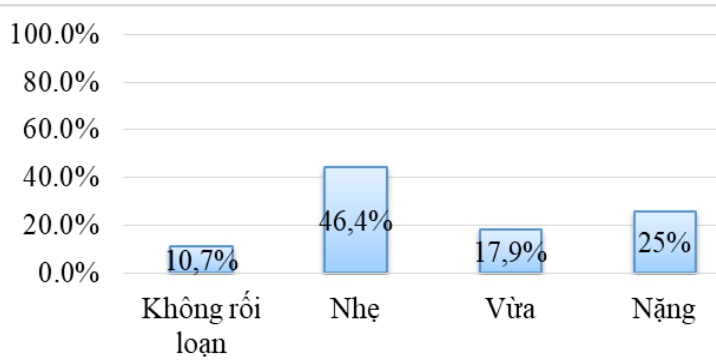

Biểu đồ 2. Phân độ rối loạn chức năng cương dương ở bệnh nhân nam theo thang điểm IIEF

$$
(n=28)
$$

Trong 28 bệnh nhân nam tham gia nghiên cứu có 13 bênh nhân ở mức rối loan nhe chiếm 46,4\%, 5 bệnh nhân $(17,9 \%)$ ở mức độ rối loạn vừa, 7 bênh nhân ở mức độ nặng chiếm $25 \%$ và chỉ có 3 bệnh nhân không có rối loạn (10,7\%).

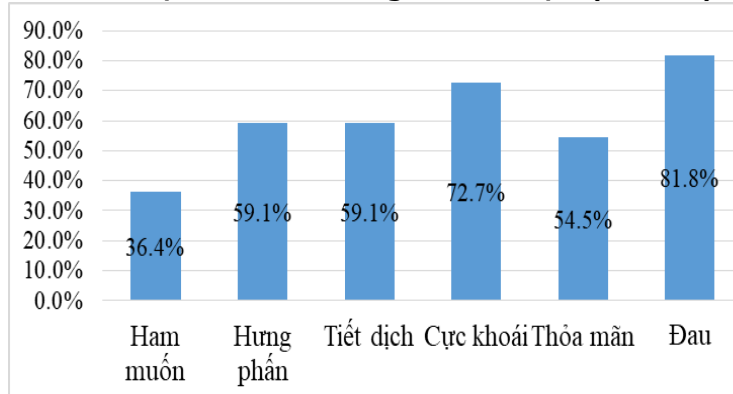

Biểu đồ 3. Tỷ lệ suy giảm chức năng tình dục của từng rối loạn theo thang điểm FSFI ở bệnh nhân nữ ( $n=22)$

Tỷ lệ rối loạn chức năng tình dục nữ là $77,3 \%$ và rối loạn phổ biến nhất là đau với $81,8 \%$, tiếp theo là cực khoái $(72,7 \%)$.

Bảng 3. Các yếu tố liên quan đến rối loạn tình dục ở bệnh nhân suy tim

\begin{tabular}{|c|c|c|c|c|c|c|}
\hline \multirow{2}{*}{\multicolumn{2}{|c|}{ Yếu tố }} & \multicolumn{2}{|c|}{$\begin{array}{c}\text { Có rối loạn tình dục } \\
(n=42)\end{array}$} & \multicolumn{2}{|c|}{$\begin{array}{c}\text { Không rối loạn tình } \\
\text { dục }(n=8)\end{array}$} & \multirow{2}{*}{$\mathbf{p}$} \\
\hline & & $\mathbf{n}$ & $\%$ & $\mathrm{n}$ & $\%$ & \\
\hline \multirow{2}{*}{ Giới tính } & Nam & 25 & 89,3 & 3 & $10,7 \%$ & \multirow{2}{*}{0,277} \\
\hline & Nữ & 17 & 77,3 & 5 & 22,7 & \\
\hline \multirow{3}{*}{ Nhóm tuổi } & $18-35$ & 4 & 44,4 & 5 & 55,6 & \multirow{3}{*}{$<0,05$} \\
\hline & $36-50$ & 14 & 82,4 & 2 & 17,6 & \\
\hline & $51-60$ & 24 & 100 & 0 & 0 & \\
\hline \multirow{2}{*}{ Địa chỉ } & Thành thị & 9 & 81,8 & 2 & 18,2 & \multirow{2}{*}{$>0,05$} \\
\hline & Nông thôn & 33 & 84,6 & 6 & 15,4 & \\
\hline
\end{tabular}


VIETNAM MEDICAL JOURNAL N01 - MAY - 2021

\begin{tabular}{|c|c|c|c|c|c|c|}
\hline \multirow{2}{*}{ Hút thuốc } & Có & 15 & 88,2 & 2 & 11,8 & \multirow{2}{*}{0,699} \\
\hline & Không & 27 & 81,8 & 6 & 18,2 & \\
\hline \multirow{2}{*}{ Rượu bia } & Có & 13 & 81,3 & 3 & 18,7 & \multirow{2}{*}{0,699} \\
\hline & Không & 29 & 85,3 & 5 & 14,7 & \\
\hline \multirow{2}{*}{ Huyết ápcao } & Có & 21 & 91,3 & 2 & 8,7 & \multirow{2}{*}{0,261} \\
\hline & Không & 21 & 77,8 & 6 & 22,2 & \\
\hline \multirow{2}{*}{ Đái tháođường } & Có & 11 & 100 & 0 & 0 & \multirow{2}{*}{0,174} \\
\hline & Không & 31 & 79,5 & 8 & 22,5 & \\
\hline \multirow{2}{*}{ Suy thận } & Có & 14 & 87,5 & 2 & 12,5 & \multirow{2}{*}{$>0,05$} \\
\hline & Không & 28 & 82,4 & 6 & 17,6 & \\
\hline
\end{tabular}

Có mối liên quan giữa nhóm tuối với rối loạn chức năng tình dục, trong đó nhóm bệnh nhân tuối 51 60 có tỷ lệ suy chức năng tình dục cao hơn có ý nghĩa so với 2 nhóm tuổi còn lại cả hai giới $(p<0,05)$.

\section{BÀN LUẬN}

Rối loạn chức năng tình dục trong suy tim mãn tính phụ thuộc vào nhiều yếu tố như tuổi tác, giới tính, thời gian mắc bệnh, tác nhân tâm lý cũng như chất lượng quan hệ với bạn tình. Một tỷ lệ lớn bệnh nhân (68\% nam và $50 \%$ nữ) báo cáo rằng các vấn đề tình dục của họ xảy ra trước khi bắt đầu các triệu chứng suy tim và trở nên tồi tệ hơn theo thời gian. Trong nghiên cứu này, $84 \%(n=42)$ bệnh nhân suy tim cho biết có các vấn đề về chức năng tình dục, $88,9 \%$ ở nam và $77,3 \%$ ở nữ.

Đối với nam giới, rối loạn chức năng tình dục được đánh giá bằng 15 câu hỏi về Chức năng Cương dương (IIEF) để đánh giá chủ yếu là ED và 19 câu hỏi FSFI được sử dụng để điều tra FSD. RLCD cũng xảy ra trong dân số nói chung, với tỷ lệ ngày càng tăng theo độ tuổi. Ở nhóm nam ( $\mathrm{n}=28)$, điểm số trung bình về chức năng cương dương (IIEF) là $35,4 \pm 17,1$, có 3 bệnh nhân không có rối loạn $(10,7 \%)$, rối loạn nhẹ chiếm 46,4\%, 5 bệnh nhân (17,9\%) ở mức độ rối loạn vừa, 7 bệnh nhân ở mức độ nặng chiếm $25 \%$. Tỷ lệ này cao hơn so với nghiên Võ Văn Thắng, 2/3 (66,9\%) có triệu chứng RLCD và chỉ $0,8 \%$ RLCD nặng[5]. Tuy nhiên, nghiên cứu này cũng tương tự với nghiên cứu về rối loạn cương ở bệnh nhân suy tim theo chủng tộc và dân tộc của Hebert $K$ với $81 \%$ bệnh nhân tim được báo cáo RLCD[10].Nhìn chung, $25 \%$ nam giới nói rằng họ không bao giờ có đủ cương cứng để thâm nhập; $91,7 \%$ nam giới cho biết có vấn đề trong việc duy trì cương cứng sau khi thâm nhập, do đó đáp ứng chẩn đoán lâm sàng về ED. Chỉ có 8,3\% nam giới cho biết không gặp bất kỳ vấn đề gì trong việc cương cứng đủ để giao hợp hoăcc duy trì sư cươning cứng cho đến khi đat cao trào.

Suy giảm chức năng tình dục nữ có thể gặp nhiều loại hơn so với nam, bao gồm suy giảm ham muốn, suy giảm hưng phấn tình dục, rối loạn cực khoái hoặc đau khi quan hệ. Trong nghiên cứu này, tổng điểm FSFI trung bình là $18,61 \pm 7,7$, trong đó rối loạn phổ biến nhất là đau với $81,8 \%$, tiếp theo là cực khoái $(72,7 \%)$. Kết quả này cao hơn so với các nghiên cứu khác trên thế giới. Theo Wen-Jia Lou (2017) cho thấy tỷ lệ mắc rối loạn tình dục ở nữ trưởng thành ở Bắc Kinh là 2973 (63,3\%) sử dụng điểm số 26,55 làm giá trị đánh giá, trong khi tổng điểm FSFI trung bình là $23,92 \pm 6,37$ trong đó tỷ lệ đau, hưng phấn, vấn đề bôi trơn âm đạo, rối loạn chức năng cực khoái và rối loạn thỏa mãn tình dục lần lượt là $46,5 \%, 80,1 \%, 32,4 \%$, $29,9 \%$ và $30,3 \%$. Tỷ lệ trong nghiên cứu này cao hơn so với những nghiên cứu khác do đối tượng nghiên cứu ở những nghiên cứu khác không mắc suy tim hoặc các bệnh khác.

Nhóm bệnh nhân tuổi 51 - 60 có tỷ lệ suy chức năng tình dục cao hơn có ý nghĩa so với 2 nhóm tuổi còn lạicảhai giới $(p<0,05)$. Kết quả trong nghiên cứu này cho thấy sự khác biệt giữa những người ở ba độ tuổi, điêuu đó chứng minh rõ ràng rằng những người ở độ tuổi lớn hơn có tỷ lệ rối loạn tình dục cao hơn nhữngngười trẻ. Có thể giải thích rằng những người ở tuổi già phải đối mặt với sự suy giảm về nhiều mặt trong sức khỏe của họ. Nhiều kết quả nghiên cứu cho thấy tỷ rối loạn tình dục tăng theo tuổi. Ở phụ nữ, theo dữ liệu nghiên cứu tại Bắc Kinh, Trung Quốc, phụ nữ sau mãn kinh có nguy cơ suy giảm chức năng tình dục cao gấp 3 lần so với người tiền mãn kinh và giảm estrogen gây khô âm đạo cũng như đau khi giao hợp có thể giải thích hiện tượng này. Ken Marumo (2008) cho biết số lượng nam giới rối loạn chức năng cương dương tăng theo tuổi và có mối tương quan đáng kể giữa tuổi và điểm số về chức năng cương dương, chức năng cực khoái, ham muốn tình dục và sự thỏa mãn khi giao hợp.

\section{KẾT LUÂ̂N}

Tỷ lệ rối loạn chức năng tình dục cao ở bênh nhân suy tim chức năng tâm thu thất trái giảm. 
Các rốiloan chủ yếu ở mức đô nhe và vừa. Rối loạn chức năng tình dục nữ và rối loạn cương dương có liên quan đến tuổi bệnh nhân suy tim.Do vậy, cần có các biện pháp cần được can thiêp sớm và kip thời để cải thiện chất lượng cuộc sống của bệnhn nhân, đặc biệt giúp cải thiện rối loạn tình dục ở bệnh nhân suy tim chức năng tâm thu thất trái giảm.

\section{TÀI LIÊU THAM KHẢO}

1. Savarese, G. and L.H. Lund, Global Public Health Burden of Heart Failure. Card Fail Rev, 2017. 3(1): p. 7-11.

2. Rosman, L., et al., Sexual health concerns in patients with cardiovascular disease. Circulation, 2014. 129(5): p. e313-6.

3. Levine, G.N., et al., Sexual activity and cardiovascular disease: a scientific statement from the American Heart Association. Circulation, 2012. 125(8): p. 1058-72.

4. Schwarz, E.R., et al., The prevalence and clinical relevance of sexual dysfunction in women and men with chronic heart failure. Int J Impot Res, 2008. 20(1): p. 85-91.
5. Van Vo, T., H.D. Hoang, and N.P. Thanh Nguyen, Prevalence and Associated Factors of Erectile Dysfunction among Married Men in Vietnam. Front Public Health, 2017. 5: p. 94.

6. Ponikowski, P., et al., 2016 ESC Guidelines for the diagnosis and treatment of acute and chronic heart failure: The Task Force for the diagnosis and treatment of acute and chronic heart failure of the European Society of Cardiology (ESC)Developed with the special contribution of the Heart Failure Association (HFA) of the ESC. Eur Heart J, 2016. 37(27): p. 2129-2200.

7. Dickstein, K., et al., ESC guidelines for the diagnosis and treatment of acute and chronic heart failure 2008: the Task Force for the diagnosis and treatment of acute and chronic heart failure 2008 of the European Society of Cardiology. Developed in collaboration with the Heart Failure Association of the ESC (HFA) and endorsed by the European Society of Intensive Care Medicine (ESICM). Eur J Heart Fail, 2008. 10(10): p. 933-89.

8. Sand, M., et al., The female sexual function index (FSFI): a potential "gold standard" measure for assessing therapeutically-induced change in female sexual function. Fertility and Sterility, 2009. 92(3): p. S129.

\section{MỐI LIÊN QUAN GIỮA THỰC TRANG KÉM KHOÁNG HOÁ MEN RĂNG (MIH) VÀ CHẤN THƯƠ'NG RĂNG SỮA, RĂNG SỮA MẤT SỚM Ở HỌC SINH 12-15 TUỔITẠI MộT SỐ TİNH THÀNH Ở VIỆT NAM}

\section{TÓM TẮT}

Một bệnh lý đang được ngành Nha khoa trên thế giới quan tâm đến nhiều đó là kém khoáng hóa men răng hàm lớn - răng cửa (MIH). Bệnh không phát hiện và điều trị kịp thời có thể dần đến những hậu quả nghiêm trọng và gây mất răng. Nghiên cứu của chúng tôi được thực hiện trên 5294 hoc sinh ở tai mốt số tỉnh cưa Việt Nam như Bình Định, Thanh Hoá và Hải Phòng nhằm mục đích xác đinh tŷ lệ mắc bệnh ở các địa phương và một số mới liên quan để có kế hoạch điều trị và dự phòng cho phù hợp. Kết quả: tỷ lệ MIH chung của nhóm học sinh là 20,1\%, trong đó $\mathrm{MIH}$ nhẹchiếm 15,2\% tổng số đối tượng nghiên cứu và tỷ lệ MIH nặng là 4,9\%.Tỷ lệ nhiễm MIH ở răng hàm lớn và răng cửa lần lượt là $10,6 \%$ và $11,4 \%$. Các học sinh có tiền sử chấn thương răng sữa, răng sữa mất sớm có nguy cơ mắc MIH cao hơnlần lượt 1,12 lần và 1,26 lần. Kết luận: tỷ lệ mắc MIH là cao, có sự khác biệt về tỷ lệ mắc bệnh giữa các lứa tuổi và vị trí răng.

Tư khóa: Kém khoáng hóa men răng, MIH, học sinh.

*Trường Đại học Y Hà Nội

Chịu trách nhiệm chính: Võ Trương Như Ngọc

Email: votruongnhungoc@gmail.com

Ngày nhận bài: 9/3/2021

Ngày phản biện khoa học: 5/4/2021

Ngày duyệt bài: 2/5/2021

\section{Võ Trương Như Ngọc*, Hoàng Bảo Duy*}

\section{SUMMARY}

RELATION BETWEEN THE MOLAR-INCISOR HYPOMINERALIZATION (MIH) AND PRIMARY TEETH TRAUMA, EARLY

PRIMARY TEETH LOSS IN 12-15 YEAR-OLD PUPILS IN SOME PROVINCES, VIETNAM

Recent researchs indicates that molar-incisor hypomineralization (MIH) is more and more popular in dental condition worldwide. It can lead to serious consequences and cause tooth loss if not detected and treated in time. There are 5294 pupils in several provinces of Vietnam such as Binh Dinh, Thanh Hoa and Hai Phong participated in our research. This study aims to determine the prevalence of the disease in the locality and relation between the MIH and primary teeth traumatisme, early primary tooth loss to build suitable prevention and treatment plans. Results: the rate of general MIH of the pupils was $20.1 \%$, mild MIH accounted for $15.2 \%$ of the study subjects and the rate of severe MIH was $4.9 \%$. The prevalence of $\mathrm{MIH}$ in the molars and incisors was $10.6 \%$ and $11.4 \%$, respectively. Pupils with a history of primary teeth trauma and primary teeth loss had the risk of $\mathrm{MIH}$ 1.12 times and 1.26 times higher, respectively. Conclusion: The incidence of $\mathrm{MIH}$ is high, there is a difference in the rate of disease between ages and tooth position. 